\title{
A large number of online friends and a high frequency of social interaction compensate for each Other's shortage in regard to perceived social support
}

\author{
Pengyan Dai ${ }^{1} \cdot$ Na Wang ${ }^{1} \cdot$ Lian Kong ${ }^{1} \cdot$ Xinyue Dong $^{1} \cdot$ Lumei Tian $^{1}$ (D) \\ Accepted: 2 February 2021 / Published online: 6 March 2021 \\ (C) The Author(s), under exclusive licence to Springer Science+Business Media, LLC part of Springer Nature 2021
}

\begin{abstract}
The present study explored the role of the number of online friends, the frequency of social interaction and their interaction in perceived social support on WeChat, a widely used social network service, among Chinese undergraduates. A total of 1396 Chinese undergraduates completed questionnaires regarding their number of friends, frequency of social interaction and perceived social support on WeChat. The results indicated that the undergraduates' number of friends was positively related to their perceived social support, but this link was significantly stronger for undergraduates with a low frequency of social interaction than for their counterparts. Similarly, a high frequency of social interaction was found to be positively associated with perceived social support, but this relationship was much stronger for undergraduates with a smaller number of friends than for their counterparts. However, undergraduates with both a large number of friends and a high frequency of social interaction did not acquire more social support than those with only one of the two online advantages. These findings suggest that the interaction between the two online factors on perceived social support should follow a compensatory pattern rather than an additive one. The theoretical and practical implications are discussed.
\end{abstract}

Keywords The number of online friends $\cdot$ Frequency of social interaction $\cdot$ Perceived social support $\cdot$ WeChat

\section{Introduction}

Perceived social support is defined as an individual's feeling that he or she is respected, supported, understood and satisfied in society (Klasen et al., 2010). It is a better predictor of people's mental health than practical social support (Kwok, Yeung, \& Chung, 2011; McDowell \& Serovich, 2007; Wang, Mann, Lloyd-Evans, Ma, \& Johnson, 2018a; Wang, $\mathrm{Nie}, \mathrm{Li}, \&$ Zhou, 2018b). As a social resource, only the available portion (e.g., perceived social support) can be described as social capital according to social capital theory (Lin, 1999; Lin, Ensel, \& Vaughn, 1981). Perceived social support has thus become a psychological research topic. Individuals with more social support gain more advantages (Frison \& Eggermont, 2015; Manago, Taylor, \& Greenfield, 2012), such

$\overline{\text { Pengyan Dai, Na Wang, Lian Kong, and Xinyue Dong are co-first }}$ authors

Lumei Tian

tianlumei@sina.com

1 School of Psychology, Shandong Normal University, No. 1 Daxue Road, Changqing Jinan 250358, People's Republic of China as family satisfaction (Drummond et al., 2016), dispositional gratitude (Zhang, Zhang, Yang, \& Li, 2017), and fewer mental health problems (Nardon, Aten, \& Gulanowski, 2015) and suicidal behaviors (Hofstra et al., 2018). Accordingly, people often seek and provide social support through social communications.

Over the past few years, with the development of the use of the Internet for communication, social networking sites (SNSs) have become important new social environments (Lima, Marques, Muiños, \& Camilo, 2017; Subrahmanyam \& Greenfield, 2008). SNSs such as Facebook and Twitter allow users to create their own profiles, access others' profiles, and establish and maintain connections with others (Ellison, Steinfield, \& Lampe, 2007; Grieve, Indian, Witteveen, Tolan, \& Marrington, 2013). Importantly, compared to real-world communication, online communication on SNSs expands individuals' social networks by greatly increasing their number of close relationships and stranger relationships (Manago et al., 2012) and facilitates the rapid distribution of content and connection to other users (Treem \& Leonardi, 2012). In other words, SNSs provide a more diverse and convenient platform to seek and provide social support than offline environments. Through online interactions, individuals can seek 
support at any given point in time, and others can easily respond (Bender, Jimenez-Marroquin, \& Jadad, 2011). Although the characteristics of network communication, such as disinhibition, lack of physical field, weak connection, high self exposure and high intimacy, make the social support felt through the network different from the social support in the real world (Mickelson, 1997; Liang \& Wei, 2008), the types and functions of social support in the offline world can also be found on the Internet (Turner, Grube, \& Meyers, 2001). As well, online social support incorporates all components of traditional (offline) social support, with the addition of entities, meanings, and nuances present in a virtual setting, and unique to computer-mediated communication (LaCoursiere, 2001; Lee, Noh, \& Koo, 2013). Previous research has found that individuals can perceive emotional support and companionship from SNSs at a level that is almost equivalent to the amount normally perceived from their live-in partners (Hampton, Goulet, Rainie, \& Purcell, 2011). Perceived social support on SNSs is very important for improving individuals' mental health and behavioral performance as well. For example, it has been found to not only enhance individuals' sense of belonging in cyberspace and thereby their psychological wellbeing and life satisfaction (Oh, Ozkaya, \& Larose, 2014) but also promote the emergence of online altruistic behaviors $(\mathrm{Li}$, Jiang, Yong, \& Zhou, 2018; Scarpa \& Haden, 2006). Thus, it is essential to pay close attention to perceived social support from SNSs in the Internet age. This is particularly critical in certain periods, such as the home isolation period for the prevention of COVID-19 infection, when people have few realworld social connections but need a large amount of support to cope with stress. In the present study, we sought to identify how individuals easily acquire this necessary support via WeChat, a widely used SNS in China.

WeChat is a mobile instant text and voice messaging communication service developed by Tencent Holdings Ltd. in China on January 21, 2011. It provides users an innovative way to communicate and interact with friends through text messaging, hold-to-talk voice messaging, one-to-many messaging, photo/video sharing, location sharing, and contact information exchange (Hou et al., 2018). Users can also interact with others in WeChat moments by clicking the "like" response to endorse content shared by friends or by receiving "likes" from friends (Kosinski, Matz, Gosling, Popov, \& Stillwell, 2015). WeChat is now the most widely used social networking service in China and has become an important social media platform for computer-mediated communication (Wang et al., 2018b). Its number of active users ranked fifth in the world and first in China in 2018 (statista.com 2018) and reached over 1.2 billion monthly from a wide range of age groups in the second quarter of 2020 (statista.com 2020). Therefore, we used WeChat as young peoples' social interaction platform to explore their social communication in the present study.
First, although online friends have varying qualities and may even be unknown (Bokhorst, Sumter, \& Westenberg, 2010; Sheets \& Mohr, 2009), a large number of friends on SNSs (hereafter referred to as the NFS) emerges as one of the strongest and most positive predictors of social support in SNS use (Oh et al., 2014; Rochelle \& Chan, 2015). According to the notion of a friends heuristic (Nabi, Prestin, \& So, 2013), Facebook users are thought to apply a heuristic based on their number of friends to evaluate their social support availability, i.e., the greater the number, the more connected individuals perceive themselves to be, regardless of the precise nature of those connections or the messages received; thus, they perceive greater levels of support. Individuals with more friends on SNSs have been shown to perceive more social support from these friends (Frison \& Eggermont, 2015; Guo, Li, \& Ito, 2014; Nabi et al., 2013). Accordingly, possessing a large NFS should be beneficial for individuals in regard to acquiring social support.

Second, the frequency of an individual's social interaction with friends or the strength of those ties should be critical for seeking and providing social support. Social interaction, also called "ties" or "interaction ties", refers to a link established via reciprocal behavior between two people (Wang \& Chiang, 2009). The strength of these ties can be defined according to the frequency of interaction: a high frequency of social interaction represents strong ties, whereas a low frequency of social interaction represents weak ties (Wright, 2000). The fact that strong ties play an indispensable role in the acquisition of social interaction has been supported by previous studies (Burke \& Kraut, 2016; Wang \& Wang, 2013). Adults who talk to those with whom they have strong-ties online have been found to experience emotional support and decreased depressive symptoms, but this is not the case when they communicate with those with whom they have weaker ties (Bessière, Kiesler, Kraut, \& Boneva, 2008; Krämer, Rösner, Eimler, Winter, \& Neubaum, 2014). Interaction with others with whom an individual has strong ties on Facebook has also been found to be associated with increases in perceived social support and reductions in stress (Burke \& Kraut, 2016). In short, social interaction, both online and offline, is positively related to social support (Chung, 2013; Wang \& Wang, 2013).

The next question is whether an individual must interact frequently with a large NFS to obtain the needed support. To go further, is there an interaction between an individual's quantity of friends and the strength of the connections with them on that individual's perceived social support? The number of friends and the level of social interaction have been recognized as two essential elements for social support seeking and provision (Lin, 1999; Lin et al., 1981; Pornsakulvanich, 2017). However, their interaction remains unclear in previous empirical research. Although strong ties are critical for acquiring social support, the importance of weak ties for obtaining social resources was also emphasized by Granovetter (1973) in his weak-ties theory. 
For example, as the number of friends increases, the heterogeneity of an individual's social networks increases; thus, individuals will have more opportunities to access better resources that are usually out of reach offline. Bian (2012) also believed that in strong ties, individuals are closer to each other, so they can acquire an adequate level of social capital through a small number of friends; however, in weak ties, the relationships between people are distant, which means that if individuals want to acquire an equivalent amount of social capital, they need a large number of friends. This view is in accordance with the perspective of compensation (Bäckman \& Dixon, 1992), which considers the possession of a large number of friends to be an effective method to compensate interpersonal losses. In other words, if an individual has only a small number of friends because of shyness, introversion, or other reasons, he or she would benefit from having strong ties with these friends; however, if an individual cannot interact with others frequently, then possessing a large number of friends, particularly on SNSs, would help the individual to perceive himself or herself as socially supported. Accordingly, social interaction levels and the NFS should compensate for each other's shortage in regard to an individual's perceived social support theoretically. In brief, we expected this interaction to follow a compensatory rather than additive pattern. The latter means that an individual having a large NFS and a high frequency of social interaction simultaneously should acquire most social support whereas the former emphasizes the compensatory role of one factor for another's shortage. Despite many positive outcomes of online social communication, there are some disadvantages of excessive using SNSs (Twenge \& Campbell, 2019; Twenge \& Martin, 2020; Twenge, Blake, Haidt, \& Campbell, 2020). For example, individuals who spend more time on electronic communication may be at increased risk of cyberbullying (Kowalski, Giumetti, Schroeder, \& Lattanner, 2014) and suicidal ideation or suicidal attempts (Twenge \& Campbell, 2019). However, moderate use of digital technology is not intrinsically harmful and may be advantageous in a connected world (Przybylski \& Weinstein, 2017). If an individual has a large NFS and frequently interacts with them simultaneously, he or she should be at risk of excessive use of the Internet. By contrast, a compensatory pattern can be regarded as reflecting moderate use of SNSs relatively. However, there is little empirical evidence to support this compensatory pattern hypothesis. Although an extensive research has provided evidence for so called "rich-get-richer" and "poor-getpoorer" Internet theories, which posit that individuals with already ample psychosocial resources in real world tend to prosper in online contexts, while vulnerable individuals further erode their well-being (Desjarlais \& Willoughby, 2010; Reer \& Krämer, 2017; Selfhout, Branje, Delsing, ter Bogt, \& Meeus, 2009; Snodgrass et al., 2018) and for social compensation theory, which suggests that socially inadequate individuals in real world can benefit from the Internet (Selfhout et al., 2009; Snodgrass et al., 2018), they focused on the role of online activities in an individual's offline developments rather than the interaction between different online behaviors on the individual's well-being. Therefore, the present study aimed to fill this gap.

Through the findings of the present study, we expected to contribute to a better understanding of the positive outcomes of online social communication on SNSs, particularly how an individual acquires needed social support from virtual environments in the Internet era. The results would help further understand how the NFS and the strength of their ties interact with each other to influence an individual's perceived social support and we expected it to follow a compensatory rather than additive pattern which would both contribute to understanding the significance of moderate use of SNSs and add new evidence of social compensatory effects. In practice, the present study should be beneficial especially for individuals who are shy, introverted, or socially withdrawn in the real world and for people who must isolate from others for some reason, such as the prevention of COVID-19, but still need social support. In addition, we expected to give young people some advice on how to make good use of SNSs to seek social support but to avoid indulging in the Internet.

\section{Method}

\section{Participants and Procedure}

The data in the present study came from a database of our national project collected in the spring of 2017. Using cluster sampling, a total of 1554 Chinese undergraduates from a normal university located in a city in eastern China participated in this survey. Some respondents $(n=158)$ were excluded from the analyses due to missing data or not having a WeChat account. The final sample involved 1396 participants, including $1125(80.59 \%)$ females. The average age of the participants was 19.79 years $(S D=1.44)$, ranging from 16 to 25 years. All of the participants were Han Chinese, who made up $91.46 \%$ of the total population in the 2015 population census of China according to the National Bureau of Statistics of People's Republic of China.

Before the survey, informed consent was obtained, and ethics approval was obtained from the research ethics boards at our university. All participants were given a series of selfreported questionnaires. It took approximately $10 \mathrm{~min}$ to complete all of the measures in the present study.

\section{Measures}

The Number of Friends Referring to Kim and Lee's research procedure (Kim \& Lee, 2011), all participants were asked to $\log$ in to their WeChat accounts and report their exact number of WeChat friends (i.e., contacts) as shown in their contact lists. On WeChat, all friends in an user's contact list must be 
accepted after a "friend" request which can be failed if rejected or ignored.

Frequency of Social Interaction Social interaction was measured using one item that asked participants to rate the frequency of their social interaction with their WeChat friends on a 5 -point Likert scale $(1=$ very little (almost none) to $5=a$ lot (almost everyday)). Higher scores indicate a higher frequency of social interaction.

Perceived Social Support The Multidimensional Perceived Social Support Scale (Dahlem, Zimet, \& Walker, 1991) was adapted to fit the WeChat context (e.g., "I can get emotional help and support from my friends via WeChat"). The scale contains 12 items that are rated on a 7-point scale $(1=$ strongly disagree to $7=$ strongly agree). The total average scores were calculated for all participants, with higher scores indicating more perceived social support. The Cronbach's alpha of this scale was 0.92 in this study.

\section{Analysis}

In the current study, analyses were performed using SPSS version 22 and Hayes's (2013) PROCESS macro. Given that gender (Nabi et al., 2013) and age (Sheets \& Mohr, 2009) have been found to be closely related to perceived social support and, in the current study, living area $(r=-0.09, p<0.01)$, father's education level $(r=0.07, p<0.01)$ and mother's education level $(r=0.08, p<0.01)$ were also found to be significantly related to perceived social support, these demographics were controlled as covariables in the analyses. First, descriptive statistical analyses and partial correlation analyses of all variables were conducted. Second, according to Hayes's (2013) recommendation, PROCESS model 1 was adopted to examine our hypothesis. Third, we ran two traditional simple slope tests and two floodlight analyses (Spiller, Fitzsimons, Lynch, \& Mcclelland, 2013) to help illustrate the results.

\section{Results}

The descriptive statistics and partial correlation results are shown in Table 1. Substantial correlations were found among these variables.

Next, regression analyses were conducted according to the specifications set out by the PROCESS macro. In line with Dearing and Hamilton's (2006) procedure, all variables were standardized to minimize multicollinearity before the data analysis. As Table 2 illustrates, the number of friends, the level of social interaction and their interaction all significantly predicted perceived social support.

We then separately plotted perceived social support for relatively low and high social interaction ( $1 S D$ below the mean and $1 S D$ above the mean, respectively) (see Fig. 1). A
Table 1 Descriptive statistics and partial correlation analysis

\begin{tabular}{llllll}
\hline Variable & $M$ & $S D$ & 1 & 2 & 3 \\
\hline 1. NFS & 75.45 & 58.63 & - & & \\
2. Social interaction & 2.72 & 0.82 & $0.11^{\text {** }}$ & - & \\
3. Perceived social support & 5.35 & 1.01 & $0.16^{\text {*** }}$ & $0.23^{\text {** }}$ & - \\
\hline
\end{tabular}

simple slope test indicated that for those undergraduates with a high frequency of social interaction, a greater number of friends was significantly associated with more perceived social support $(\beta=0.11, p<0.05)$. This association was also significant and stronger $(\beta=0.18, p<0.001)$ for those with a low frequency of social interaction, indicating that a larger number of friends was particularly beneficial to them.

Similarly, another simple slope test indicated that for undergraduates with either a small or large number of friends, the frequency of their social interaction was positively and significantly associated with their perceived social support $(\beta=$ $0.19, p<0.001 ; \beta=0.12, p<0.05$ ). However, the relationship was much stronger for undergraduates with a smaller number of friends, indicating that a high frequency of social interaction was particularly beneficial to them.

In order to find out the point that the number of friends can be compensated by the frequency of social interaction, we further used the Johnson-Neyman method (J-N method for short) to do the simple slope test. By fixing the $t$ value to the critical value, the J-N plot provides more information than the pick-a-point plot of the simple slopes in that it provides the regions of significance and nonsignificance for the moderator (Spiller et al., 2013). The results (see Fig. 2) indicated that, when the frequency of social interaction was less than 1.22 units, the simple slope of the NFS on perceived social support was positive and significantly different from zero, but not for the frequency of social interaction greater than 1.22 ,

Table 2 Testing the interaction effects of NFS and social interaction on perceived social support

\begin{tabular}{llll}
\hline Predictors & $\beta$ & $t$ & $95 \%$ confidence interval \\
\hline Age & -0.03 & -1.88 & {$[-0.078,0.002]$} \\
Gender & -0.30 & $-4.68^{* * * *}$ & {$[-0.428,-0.175]$} \\
Living area & -0.08 & -1.31 & {$[-0.195,0.039]$} \\
Father's education level & 0.03 & 0.60 & {$[-0.061,0.115]$} \\
Mother's education level & 0.02 & 0.35 & {$[-0.080,0.115]$} \\
NFS & 0.14 & $5.30^{* * *}$ & {$[0.090,0.196]$} \\
Social interaction & 0.22 & $8.38^{* * *}$ & {$[0.166,0.268]$} \\
NFS $\times$ social interaction & -0.06 & $-2.20^{* *}$ & {$[-0.106,-0.006]$} \\
$R^{2}$ & 0.10 & & \\
$F$ & 19.70 & & \\
\hline
\end{tabular}


Fig. 1 The interaction of NFS and frequency of social interaction on perceived social support. Note. All values were standardized in the analyses. The same below

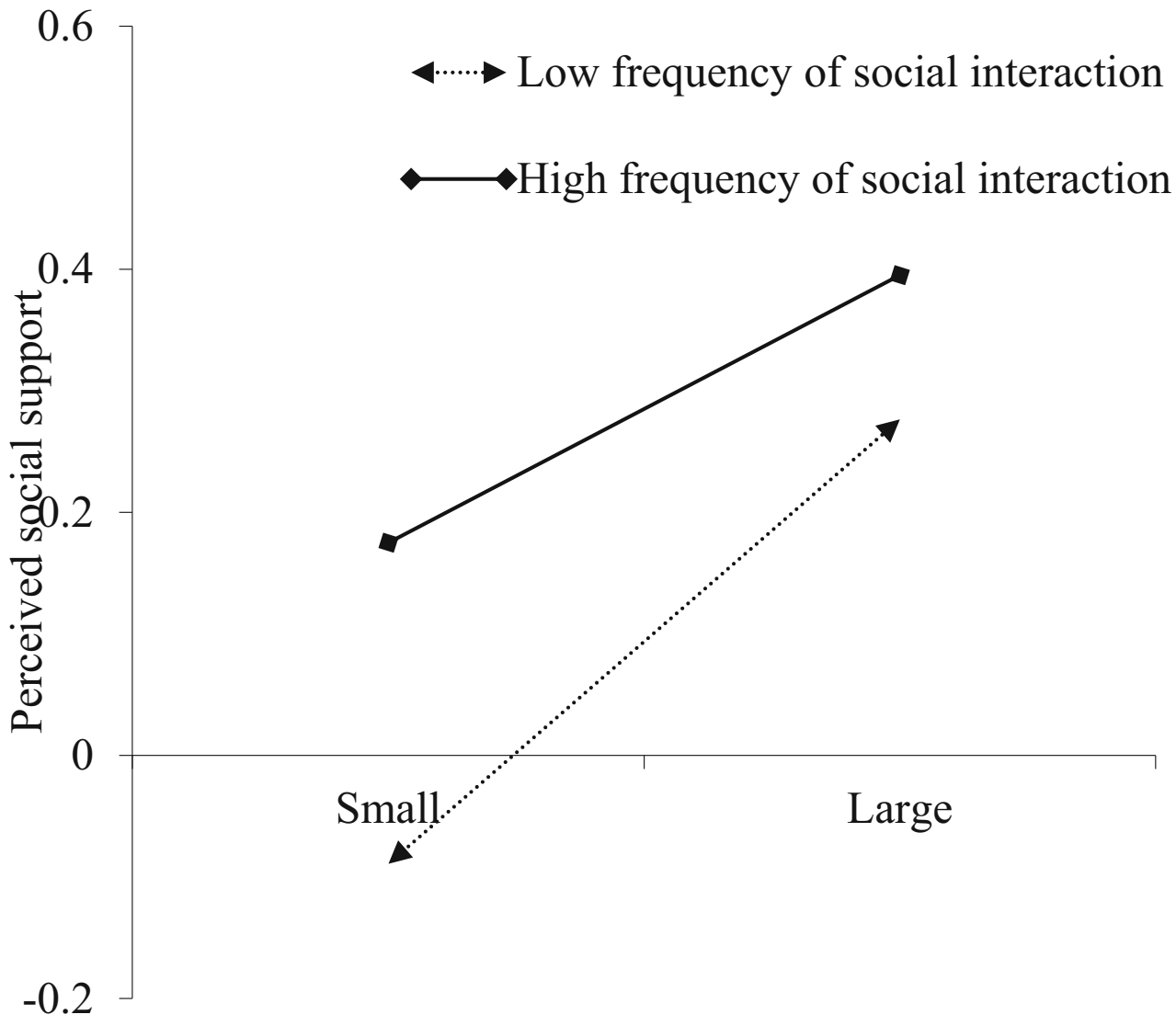

NFS indicating that a decrease in the frequency of social interaction resulted in a statistically significant increase in the link between the NFS and social support. By contrast, the higher the frequency of social interaction, the weaker relationship between the number of friends and perceived social support.

Similarly, another simple slope test using J-N method indicated that when the NFS was less than 1.26 units, the simple slope of the frequency of social interaction on perceived social support was positive and significantly different from zero, but not for the NFS in the regions of [1.26, 2.97], indicating that a decrease in the number of friends resulted in a statistically significant increase in the association between the frequency of social interaction and social support. By contrast, the larger the number of friends, the weaker relationship between the
Fig. 2 Johnson-Neyman plot of the simple slope of the NFS on perceived social support at the average value $(0)$ of the NFS across the range of the frequency of social interaction

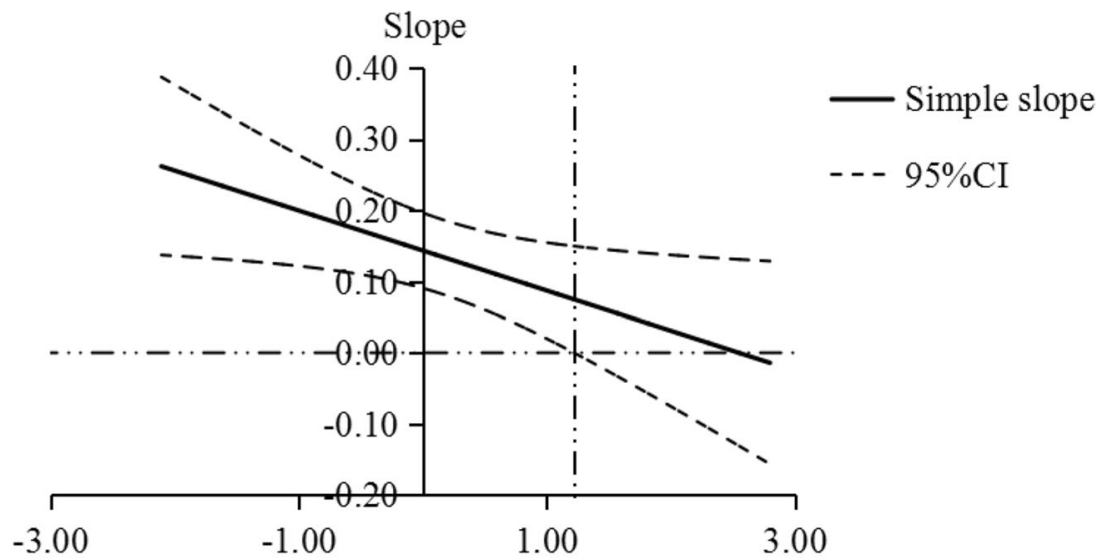

The frequency of social interaction 
frequency of social interaction and perceived social support was.

In order to further test our hypothesis, we also ran a oneway ANOVA and multiple comparisons to compare the differences among the four different combined conditions of the NFS and the frequency of social interaction. The results showed that there was a significant difference among the four conditions $(F(3,70)=8.04, p<.001)$, and the individuals who have either a large NFS or a high interaction frequency or both of them all reported significantly more social support than those who have a small NFS and a low frequency simultaneously $\left(M_{\text {Large-high }}-M_{\text {Small-low }}=1.45, p<0.001\right.$, Cohen' $d=1.40 ; M_{\text {Small-high }}-M_{\text {Small-low }}=.85, p<0.05$, Cohen' $d=$ $0.70 ; M_{\text {Large-low }}-M_{\text {Small-low }}=.87, p<0.05$, Cohen' $d=0.75$ ), but no significant differences were found among the three conditions ( $p s>0.05)$.

\section{Discussion}

The present study tested the interaction model and found some significant results.

First, as predicted, the number of friends was found to be positively related to perceived social support, which is consistent with previous findings about Facebook (Frison \& Eggermont, 2015; Guo et al., 2014). This result can be explained by the fact that SNSs build a diverse platform for users to establish and maintain connections with their online friends (Ellison et al., 2007) and that a large NFS provides a large number of opportunities to exercise social skills (Song et al., 2014), enhance social participation (Kalpidou, Costin, \& Morris, 2011) and seek social support (Nabi et al., 2013). Friendship is an important source of social support for undergraduates (Collins \& Laursen, 2004).

Second, social interaction was also found to be positively related to perceived social support, which is consistent with previous findings (Bessière et al., 2008; Burke \& Kraut, 2016; Chung, 2013; Sheets \& Mohr, 2009; Wang \& Wang, 2013). This is because frequent social interaction is conducive to establishing and consolidating strong ties that can provide more effective social support, whereas individuals obtain relatively less social support from friends with whom they do not interact frequently (Yen, Yen, Chen, Chen, \& Ko, 2007).

Third and importantly, a compensatory rather than additive interaction pattern between the number of friends and social interaction on perceived social support was also found, which is consistent with our hypothesis. Specifically, a large number of friends is particularly beneficial to obtaining social support for undergraduates who have a low frequency of social interaction, while undergraduates with a small number of friends can obtain compensation from a high frequency of social interaction. First, strong ties play an indispensable role in the acquisition of social interaction (Burke \& Kraut, 2016; Wang
\& Wang, 2013) and are particularly helpful in seeking emotional support (Bessière et al., 2008). Individuals with strong ties could obtain relatively adequate social support from only a small number of friends. In other words, college students with a small number of friends could acquire needed social support by strong ties with them. However, strong ties cannot be considered to be a bonus and is not necessary for those individuals with a large NFS, because college students with both a large NFS and a high frequency of social interaction were not significantly different in perceived social support from those with only one of them. Even, the higher the frequency, the weaker the relationship between the NFS and social support was. By contrast, if individuals with weak ties want to obtain equal social capital, their possession of a large NFS is indispensable because they interact less with their online friends and are estranged from them, which means that a large NFS can provide more opportunities to access the assistance or additive support that they need (Bian, 2012). According to the weak-ties theory (Granovetter, 1973), the more friends an individual has, the more heterogenous his or her individual social networks are, and the more opportunities the individual will have to access better resources. This view is consistent with previous findings about Facebook (Lee, 2013; Manago et al., 2012; Rozzell et al., 2004). Additionally, from the perspective of compensation (Bäckman \& Dixon, 1992), the low frequency of social interactions with online friends is regarded as a type of interpersonal loss, which leads to the failure of individuals to build a solid relationship with others (Desjarlais \& Willoughby, 2010) and to less overall social support. However, organisms' self-protection mechanism can compensate for this loss through behavior substitution (Bäckman \& Dixon, 1992), such as becoming acquainted with a larger NFS. Similarly, however, a large number of friends has no additional boon to those young people with strong ties with friends. Therefore, either a large NFS or strong ties with friends are enough but both of them have no extra benefits for seeking social support. The interaction showed a compensatory rather than additive pattern. Although the "rich-getricher" hypothesis proposed by Kraut et al. (2002) states that especially extroverted users with high social skills and large preexisting social networks are the ones that could socially benefit from the Internet (Reer \& Krämer, 2017) and the "poor-get-poorer" hypothesis also indicates that individuals with low social skills in real world further erode their adaptation in online contexts (Selfhout et al., 2009; Snodgrass et al., 2018), our findings suggest that those individuals without good social skills, despite offline or online, can also benefit from the Internet in regard to perceived social support through strong ties with a small NFS as a compensatory way.

Taken together, the current study provides valuable information by examining the interaction of the number of online friends and the frequency of social interaction on perceived social support on WeChat among college students. First, the 
results highlight the compensatory role of the quantity of online friends and the strength of social ties for each other on an individual's perceived social support, thereby providing important empirical evidence for the relevant theories such as weak-ties theory (Granovetter, 1973) and the perspective of compensation (Bäckman \& Dixon, 1992). Second, the findings support our compensatory rather than additive interaction hypothesis, which implies the significance of moderate use of SNSs on social support seeking in the Internet age and extends previous research on how different Internet activities influence their access to social support in online contexts. Third, different from "rich-get-richer" or "poor-get-poorer" thinking and social compensatory theory which all concern whether Internet is beneficial or harmful to users' real-world developments, our findings suggest that a social compensatory effect also exists between different Internet activities in an online environment rather than only occurs between online and offline contexts.

These findings have important implications as well, not only for future studies, but also for college students and their parents, educators, and practitioners interested in their social media use for social support purposes. First, they may be especially meaningful for individuals who are shy, introverted, or socially withdrawn because they suggest that frequent social interaction with a small number of online friends is sufficient to obtain social support, whereas a large number of friends would be particularly beneficial for people with less social interaction with others. It suggests that a socially inadequate individual can acquire needed social support from online communication only by either keeping strong ties with a small number of friends or keeping a large number of friends but not necessarily to frequently contact with them. Second, the findings address the Internet age, in which online social networking plays an increasingly important role in people's social life. They should be particularly meaningful for people who must be isolated from others for reasons such as the prevention of COVID-19 infection and who therefore have few real-word social connections but need great support to cope with stress. These people have to rely on the Internet to access social support and our findings tell them it may be enough to only keep a strong link with a small number of online friends. Lastly, the findings suggest that young people, particularly college students, should use SNSs moderately and not indulge in the Internet. Both making a large NFS and keeping in close touch with them have no extra benefits for seeking social support. Instead, it may increase risk of Internet social addiction.

Several limitations must be considered. First, the present study adopted a cross-sectional design, which made it difficult to draw causal conclusions. Further studies should use experimental or longitudinal designs to seek evidence of causal assumptions. Second, the measurement of social interaction may be reconsidered in the future. We focused on the frequency of social interaction because it reflects the strength of ties we were interested in. Although it is positively and significantly related to the quality of the interactions (Blom, Marschark, Vervloed, \& Knoors, 2014; Chang \& Chuang, 2011; Hou, 2018; Nguyet, Chang, Celine, Maurice, \& Tom, 2018), they are not the same. Therefore, it is worthy of studying the interaction between an individual's quantity of friends and the quality of the interactions using a more suitable measurement in the future. Furthermore, it was measured by only one item, which may reduce the accuracy and reliability of this measurement. Further studies should develop a more reliable questionnaire with multiple items to improve the reliability of the results. Third, a gender ratio imbalance existed in the sample because the proportion of females was too high, and the sample was limited to only one university, neither of which are representative traits. Further studies should expand the sampling scope and balance the gender ratio if possible to further increase the generalizability of the findings. At last, it should be pointed out that online support can not substitute the physical contact and offline support which is limited during the pandemic, though there are similarities between offline social support and online social support. As Lin et al. (2017) pointed out, offline social support as a strong network tie is able to alleviate stress and brings out a positive psychosocial effect; however, online social support reflects a weak network tie due to its superficial nature, distancing proximity, and inability to provide concrete assistance. Furthermore, offline social support can reduce the chances of developing a problematic internet use, whereas online social support can increase them (Mazzoni, Baiocco, Cannata, \& Dimas, 2016). Accordingly, we believe online social support can supplement to, if required, but not substitute real-world support.

Code Availability Not applicable.

Authors' Contributions Lumei Tian provided conception and design of this study. Pengyan Dai revised the manuscript substantially. Na Wang drafted the manuscript. Lian Kong revised the manuscript critically for important intellectual content. Xinyue Dong participated the original design of this study, collected and analyzed data. All authors approved the final version to be published.

Funding This work was supported by the National Social Science Fund of China (Grant No. 16BSH103).

Data Availability The datasets generated during and/or analyzed during the current study are available from the corresponding author on reasonable request.

\section{Declarations}

Ethics Approval All procedures performed in studies involving human participants were in accordance with the ethical standards of the institutional and national research committees and with the 1964 Helsinki declaration and its later amendments or comparable ethical standards. 
Informed Consent Informed consent was obtained from all individual participants included in the study.

Consent to Participate Informed consent was obtained from all individual participants included in the study.

Consent for Publication The authors consented to the submission of the manuscript to the journal.

Conflict of Interest Authors have no conflicts of interest to report.

\section{References}

Bäckman, L., \& Dixon, R. A. (1992). Psychological compensation: A theoretical framework. Psychological Bulletin, 112(2), 259-283. https://doi.org/10.1037/0033-2909.112.2.259.

Bender, J. L., Jimenez-Marroquin, M. C., \& Jadad, A. R. (2011). Seeking support on Facebook: A content analysis of breast cancer groups. Journal of Medical Internet Research, 13(1), e16. https://doi.org/10. 2196/jmir.1560.

Bessière, K., Kiesler, S., Kraut, R., \& Boneva, B. S. (2008). Effects of internet use and social resources on changes in depression. Information Communication \& Society, 11(1), 47-70. https://doi. org/10.1080/13691180701858851.

Bian, Y. (2012). Social network and status obtained. Beijing: Social Science Literature House.

Blom, H., Marschark, M., Vervloed, P. J., \& Knoors, H. (2014). Finding friends online: Online activities by deaf students and their well-being. PLoS One, 9(2), e88351. https://doi.org/10.1371/journal.pone. 0088351.

Bokhorst, C. L., Sumter, S. R., \& Westenberg, P. M. (2010). Social support from parents, friends, classmates, and teachers in children and adolescents aged 9 to 18 years: Who is perceived as most supportive? Social Development, 19(2), 417-426. https://doi.org/10. 1111/j.1467-9507.2009.00540.x.

Burke, M., \& Kraut, R. E. (2016). The relationship between Facebook use and well-being depends on communication type and tie strength. Journal of Computer-Mediated Communication, 21(4), 265-281. https://doi.org/10.1111/jcc4.12162.

Chang, H. H., \& Chuang, S. S. (2011). Social capital and individual motivations on knowledge sharing: Participant involvement as a moderator. Information \& Management, 48(1), 9-18. https://doi. org/10.1016/j.im.2010.11.001.

Chung, J. E. (2013). Social interaction in online support groups: Preference for online social interaction over offline social interaction. Computers in Human Behavior, 29(4), 1408-1414. https://doi. org/10.1016/j.chb.2013.01.019.

Collins, W. A., \& Laursen, B. (2004). Changing relationships, changing youth: Interpersonal contexts of adolescent development. Journal of Early Adolescence, 24(1), 55-62. https://doi.org/10.1177/ 0272431603260882 .

Dahlem, N. W., Zimet, G. D., \& Walker, R. R. (1991). The multidimensional scale of perceived social support: A confirmation study. Journal of Clinical Psychology, 47(6), 756-761. https://doi.org/10. 1002/1097-4679(199111)47:6<756::AID-JCLP2270470605>3.0. CO;2-L

Dearing, E., \& Hamilton, L. C. (2006). V. Contemporary advances and classic advice for analyzing mediating and moderating variables. Monographs of the Society for Research in Child Development, 71(3), 88-104. https://doi.org/10.1111/j.1540-5834.2006.00406.x.

Desjarlais, M., \& Willoughby, T. (2010). A longitudinal study of the relation between adolescent boys and girls' computer use with friends and friendship quality: Support for the social compensation or the rich-get-richer hypothesis? Computers in Human Behavior, 26(5), 896-905. https://doi.org/10.1016/j.chb.2010.02.004.

Drummond, S., Odriscoll, M. P., Brough, P., Kalliath, T., Siu, O. L., Timms, C., et al. (2016). The relationship of social support with well-being outcomes via work-family conflict: Moderating effects of gender, dependants and nationality. Human Relations, 70(5), 544-565. https://doi.org/10.1177/0018726716662696.

Ellison, N. B., Steinfield, C., \& Lampe, C. (2007). The benefits of Facebook "friends:" social capital and college students' use of online social network sites. Journal of Computer-Mediated Communication, 12(4), 1143-1168. https://doi.org/10.1111/j.10836101.2007.00367.x.

Frison, E., \& Eggermont, S. (2015). The impact of daily stress on adolescents' depressed mood: The role of social support seeking through Facebook. Computers in Human Behavior, 44, 315-325. https://doi.org/10.1016/j.chb.2014.11.070.

Granovetter, M. S. (1973). The strength of weak ties. American Journal of Sociology, 78(6), 1360-1380. https://doi.org/10.1086/225469.

Grieve, R., Indian, M., Witteveen, K., Tolan, G. A., \& Marrington, J. (2013). Face-to-face or Facebook: Can social connectedness be derived online? Computers in Human Behavior, 29(3), 604-609. https://doi.org/10.1016/j.chb.2012.11.017.

Guo, Y., Li, Y., \& Ito, N. (2014). Exploring the predicted effect of social networking site use on perceived social capital and psychological well-being of Chinese international students in Japan. Cyberpsychology, Behavior and Social Networking, 17(1), 52-58. https://doi.org/10.1089/cyber.2012.0537.

Hampton, K., Goulet, L. S., Rainie, L., \& Purcell, K. (2011). Social networking sites and our lives. Washington, DC: Pew Research Center's Internet \& American Life Project.

Hayes, A. F. (2013). Introduction to mediation, moderation, and conditional process analysis: A regression-based approach. New York: Guilford Press.

Hofstra, E., Elfeddali, I., Bakker, M., de Jong, J. J., van Nieuwenhuizen, C., \& van der Feltz-Cornelis, C. M. (2018). Springtime peaks and Christmas troughs: A national longitudinal population-based study into suicide incidence time trends in the Netherlands. Frontiers in psychiatry, 9, 45. https://doi.org/10.3389/fpsyt2018.00045.

Hou, Y. B. (2018). Social psychology. Beijing: Peking University Press.

Hou, J., Ndasauka, Y., Pan, X., Chen, S., Xu, F., \& Zhang, X. (2018). Weibo or WeChat? Assessing preference for social networking sites and role of personality traits and psychological factors. Frontiers in. Psychology, 9, 545. https://doi.org/10.3389/fpsyg.2018.00545.

Kalpidou, M., Costin, D., \& Morris, J. (2011). The relationship between Facebook and the well-being of undergraduate college students. Cyberpsychology, Behavior and Social Networking, 14(4), 18-31. https://doi.org/10.1089/cyber.2010.0061.

Kim, J., \& Lee, J. E. (2011). The Facebook paths to happiness: Effects of the number of Facebook friends and self-presentation on subjective well-being. Cyberpsychology, Behavior and Social Networking, 14(6), 359-364. https://doi.org/10.1089/cyber.2010.0374.

Klasen, F., Oettingen, G., Daniels, J., Post, M., Hoyer, C., \& Adam, H. (2010). Posttraumatic resilience in former Ugandan child soldiers. Child Development, 81(4), 1096-1113. https://doi.org/10.1111/j. 1467-8624.2010.01456.x.

Kowalski, R. M., Giumetti, G. W., Schroeder, A. N., \& Lattanner, M. R. (2014). Bullying in the digital age: A critical review and metaanalysis of cyberbullying research among youth. Psychological Bulletin, 140(4), 1073-1137. https://doi.org/10.1037/a0035618.

Kosinski, M., Matz, S. C., Gosling, S. D., Popov, V., \& Stillwell, D. (2015). Facebook as a research tool for the social sciences opportunities, challenges, ethical considerations, and practical guidelines. American Psychologist, 70(6), 543-556. https://doi.org/10.1037/ a0039210.

Krämer, N., Rösner, L., Eimler, S., Winter, S., \& Neubaum, G. (2014). Let the weakest link go! Empirical explorations on the relative 
importance of weak and strong ties on social networking sites. Societies, 4(4), 785-809. https://doi.org/10.3390/soc4040785.

Kraut, R., Kiesler, S., Boneva, B., Cummings, J., Helgeson, V., \& Crawford, A. (2002). Internet paradox revisited. Journal of Social Issues, 58(1), 49-74. https://doi.org/10.1111/1540-4560.00248.

Kwok, S. Y.C. L., Yeung, D. Y.L., \& Chung, A. (2011). The moderating role of perceived social support on the relationship between physical functional impairment and depressive symptoms among Chinese nursing home elderly in Hong Kong. Scientific World Journal, 11, 1017-1026. https://doi.org/10.1100/tsw.2011.93.

LaCoursiere, S. (2001). A theory of online social support. Advances in Nursing Science, 24(1), 60-77. https://doi.org/10.1097/00012272200109000-00008.

Lee, K. T., Noh, M. J., \& Koo, D. M. (2013). Lonely people are no longer lonely on social networking sites: The mediating role of selfdisclosure and social support. Cyberpsychology, Behavior and Social Networking, 16(6), 413-418. https://doi.org/10.1089/cyber. 2012.0553

Lee, D. Y. (2013). The role of attachment style in building social capital from a social networking site: The interplay of anxiety and avoidance. Computers in Human Behavior, 29(4), 1499-1509. https://doi. org/10.1016/j.chb.2013.01.012.

Li, R. Y., Jiang, T., Yong, J., \& Zhou, H. Y. (2018). College students' interpersonal relationship and empathy level predict internet altruistic behavior-Empathy level and online social support as mediators. Psychology and Behavioral Sciences, 7(1), 1-7. https://doi.org/10.11648/j.pbs.20180701.11.

Lima, M. L., Marques, S., Muiños, G., \& Camilo, C. (2017). All you need is Facebook friends? Associations between online and face-to-face friendships and health. Frontiers in Psychology, 8. https://doi.org/ 10.3389/fpsyg.2017.00068.

Lin, N. (1999). Social networks and status attainment. Annual Review of Sociology, 25, 467-487.

Lin, N., Ensel, W. M., \& Vaughn, J. C. (1981). Social resources and strength of ties: Structural factors in occupational status attainment. American Sociological Review, 46(4), 393-405. https://doi.org/10. 2307/2095260.

Lin, M. P., You, J., Ren, Y., Wu, J. Y. W., Hu, W. H., Yen, C. F., \& Zhang, X. (2017). Prevalence of nonsuicidal self-injury and its risk and protective factors among adolescents in Taiwan. Psychiatry Research, 255, 119-127. https://doi.org/10.1016/j.psychres.2017. 05.028.

Liang, X. Y., \& Wei, L. (2008). A preliminary study on the evaluation of college students' network social support (in Chinese). Journal of Psychological Science, 31(3), 689-691.

Manago, A. M., Taylor, T., \& Greenfield, P. M. (2012). Me and my 400 friends: The anatomy of college students' Facebook networks, their communication patterns, and well-being. Developmental Psychology, 48(2), 369-380. https://doi.org/10.1037/a0026338.

Mazzoni, E., Baiocco, L., Cannata, D., \& Dimas, I. (2016). Is internet the cherry on top or a crutch? Offline social support as moderator of the outcomes of online social support on problematic internet use. Computers in Human Behavior, 56(3), 369-374. https://doi.org/ 10.1016/j.chb.2015.11.032.

McDowell, T. L., \& Serovich, J. M. (2007). The effect of perceived and actual social support on the mental health of HIV-positive persons. AIDS Care, 19(10), 1223-1229. https://doi.org/10.1080/ 09540120701402830.

Mickelson, K. D. (1997). Seeking social support: Parents in electronic support groups. In S. Kiesler (Ed.), Culture of the Intertnet (pp. 157178). Mahwah: Erlbaum.

Nabi, R. L., Prestin, A., \& So, J. (2013). Facebook friends with (health) benefits? Exploring social network site use and perceptions of social support, stress, and well-being. Cyberpsychology, Behavior and Social Networking, 16(10), 721-727. https://doi.org/10.1089/ cyber.2012.0521.
Nardon, L., Aten, K., \& Gulanowski, D. (2015). Expatriate adjustment in the digital age: The co-creation of online social support resources through blogging. International Journal of Intercultural Relations, 47, 41-55. https://doi.org/10.1016/j.ijintrel.2015.04.001.

Nguyet, D. A., Chang, Z., Celine, C., Maurice, D. G., \& Tom, V. (2018) Adult learners' social connectedness and online participation: The importance of online interaction quality. Studies in Continuing Education, 41, 1-21. https://doi.org/10.1080/0158037X.2018. 1518899.

Oh, H. J., Ozkaya, E., \& Larose, R. (2014). How does online social networking enhance life satisfaction? The relationships among online supportive interaction, affect, perceived social support, sense of community, and life satisfaction. Computers in Human Behavior, 30, 69-78. https://doi.org/10.1016/j.chb.2013.07.053.

Pornsakulvanich, V. (2017). Personality, attitudes, social influences, and social networking site usage predicting online social support. Computers in Human Behavior, 76, 255-262. https://doi.org/10. 1016/j.chb.2017.07.021.

Przybylski, A. K., \& Weinstein, N. (2017). A large-scale test of the goldilocks hypothesis: Quantifying the relations between digitalscreen use and the mental well-being of adolescents. Psychological Science, 28(2), 204-215.

Reer, F., \& Krämer, N. C. (2017). The connection between introversion/ extroversion and social capital outcomes of playing world of warcraft. Cyberpsychology, Behavior and Social Networking, 20(2), 97-103. https://doi.org/10.1089/cyber.2016.0439.

Rochelle, T. L., \& Chan, O. F. (2015). Determinants on the quality of social networks among Hong Kong Chinese. Journal of General Psychology, 142(1), 34-47. https://doi.org/10.8000/221309.2014. 966049.

Rozzell, B., Piercy, C. W., Carr, C. T., King, S., Lane, B. L., Tornes, M., et al. (2004). Notification pending: Online social support from close and nonclose relational ties via Facebook. Computers in Human Behavior, 38, 272-280. https://doi.org/10.1016/j.chb.2014.06.006.

Selfhout, M. H., Branje, S. J., Delsing, M., ter Bogt, T. F., \& Meeus, W. H. (2009). Different types of Internet use, depression, and social anxiety: The role of perceived friendship quality. Journal of Adolescence, 32(4), 819-833. https://doi.org/10.1016/j. adolescence.2008.10.011.

Snodgrass, J. G., Bagwell, A., Patry, J. M., Dengah, H. J. F. I., SmarrFoster, C., Van Oostenburg, M., et al. (2018). The partial truths of compensatory and poor-get-poorer internet use theories: More highly involved videogame players experience greater psychosocial benefits. Computers in Human Behavior, 78, 10-25. https://doi.org/10. 13140/RG.2.2.26701.13286.

Scarpa, A., \& Haden, S. C. (2006). Community violence victimization and aggressive behavior: The moderating effects of coping and social support. Aggressive Behavior, 32(5), 502-515. https://doi.org/ 10.1002/ab.20151.

Sheets, R. L., \& Mohr, J. J. (2009). Perceived social support from friends and family and psychosocial functioning in bisexual young adult college students. Journal of Counseling Psychology, 56(1), 152 163. https://doi.org/10.1037/0022-0167.56.1.152.

Song, H., Zmyslinski-Seelig, A., Kim, J., Drent, A., Victor, A., \& Omori, K. (2014). Does Facebook make you lonely? A meta-analysis. Computers in Human Behavior, 36, 446-452.

Spiller, S. A., Fitzsimons, G. J., Lynch, J. G., \& Mcclelland, G. (2013). Spotlights, floodlights, and the magic number zero: Simple effects tests in moderated regression. Journal of Marketing Research, 50(2), 277-288. https://doi.org/10.1509/jmr.12.0420.

Subrahmanyam, K., \& Greenfield, P. M. (2008). Virtual worlds in development: Implications of social networking sites. Journal of Applied Developmental Psychology, 29(6), 417-419. https://doi.org/10. 1016/j.appdev.2008.07.004. 
Treem, J. W., \& Leonardi, P. M. (2012). Social media use in organizations: Exploring the affordances of visibility, editablity, persistence, and association. Communication Yearbook, 36(1), 143-189.

Turner, J. W., Grube, A., \& Meyers, J. (2001). Developing an optimal match within online communities: An exploration of CMC support communities and traditional support. Journal of Communication, 55, 231-251. https://doi.org/10.1111/j.1460-2466.2001.tb02879.x.

Twenge, J. M., \& Campbell, W. K. (2019). Media use is linked to lower psychological well-being: Evidence from three datasets. Psychiatric Quarterly, 90(2), 311-331. https://doi.org/10.1007/s11126-01909630-7.

Twenge, J. M., \& Martin, G. N. (2020). Gender differences in associations between digital media use and psychological well-being: Evidence from three large datasets. Journal of Adolescence, 79, 91-102. https://doi.org/10.1016/j.adolescence.2019.12.018.

Twenge, J. M., Blake, A. B., Haidt, J., \& Campbell, W. K. (2020). Commentary: Screens, teens, and psychological well-being: Evidence from three time-use-diary studies. Frontiers in Psychology, 11, 181. https://doi.org/10.3389/fpsyg.2020.00181.

Wang, J., \& Chiang, M. (2009). Social interaction and continuance intention in online auctions: A social capital perspective. Decision Support Systems, 47(4), 466-476. https://doi.org/10.1016/j.dss. 2009.04.013.

Wang, E. S., \& Wang, M. C. (2013). Social support and social interaction ties on internet addiction: Integrating online and offline contexts. Cyberpsychology, Behavior and Social Networking, 16(11), 843849. https://doi.org/10.1089/cyber.2012.0557.
Wang, Y. N., Nie, R. H., Li, Z. Y., \& Zhou, N. (2018b). WeChat moments use and self-esteem among Chinese adults: The mediating roles of personal power and social acceptance and the moderating roles of gender and age. Personality \& Individual Differences, 131, 31-37. https://doi.org/10.1016/j.paid.2018.04.012.

Wang, J., Mann, F., Lloyd-Evans, B., Ma, R., \& Johnson, S. (2018a). Associations between loneliness and perceived social support and outcomes of mental health problems: A systematic review. $B M C$ Psychiatry, 18(1), 156. https://doi.org/10.1186/s12888-018-1736-5.

Wright, K. (2000). Perceptions of on-line support providers: An examination of perceived homophily, source credibility, communication and social support within online support groups. Communication Quarterly, 48(1), 44-59.

Yen, J., Yen, C., Chen, C., Chen, S., \& Ko, C. (2007). Family factors of internet addiction and substance use experience in Taiwanese adolescents. Cyberpsychology \& Behavior, 10(3), 323-329. https://doi. org/10.1089/cpb.2006.9948.

Zhang, L., Zhang, S., Yang, Y., \& Li, C. (2017). Attachment orientations and dispositional gratitude: The mediating roles of perceived social support and selfesteem. Personality and Individual Differences, 114, 193-197. https://doi.org/10.1016/j.paid.2017.04.006.

Publisher's Note Springer Nature remains neutral with regard to jurisdictional claims in published maps and institutional affiliations. 